\title{
Avatares del testimonio en América Latina: tensiones, contradicciones, relecturas...
}

Avatars of testimony in Latin America: tensions, contradictions, rereadings...

\section{Presentación del número especial}

\author{
Jaume Peris BlaneS \\ UNIVERSITAT DE VALÈNCIA · jaume.peris@uv.es \\ GEMA PALAZÓN SÁEZ \\ UNIVERISTÉ DE LILLE III · gema.palazon@gmail.com
}

DOI: $10.7203 /$ KAM.6.7818

ISSN: 2340-1869

En una de las colaboraciones que presentamos en este número, Pilar Calveiro afirma: "creo que hablar de 'el testimonio', en términos generales, no es de mayor utilidad. Es necesario precisar: testimonio de qué y de quién y, sobre todo, para qué”. Alude con esa consideración al carácter histórico y situado de las escrituras testimoniales en las luchas culturales, sociales y políticas del mundo contemporáneo y a la necesidad de evaluar y analizar la función específica que cada testimonio desempeña en ellas. Ese enfoque, que busca desnaturalizar la categoría de testimonio tal como parece haberse consolidado en las últimas décadas, es precisamente el que sostenía la convocatoria que ha dado lugar al trabajo colectivo que aquí presentamos.

La categoría de 'Testimonio' ha servido, en las últimas décadas, para recubrir una amplia gama de escrituras, prácticas y gestos muy diferentes entre sí, pero que han transformado, en buena medida, la relación entre cultura, realidad política e intervención social en América Latina. A pesar de su indefinición conceptual, o quizás gracias a ella, la idea de 'Testimonio' ha servido en diferentes contextos 
geográficos y sociales para nombrar prácticas culturales de denuncia y disidencia política, ligadas a proyectos de visibilización de colectivos y situaciones ignoradas por las narrativas y medios oficiales. En ese sentido, las escrituras testimoniales han desempeñado, sin duda, un papel crucial en la comprensión de algunas luchas y movilizaciones sociales fundamentales en la historia reciente de América Latina.

Pero también, en determinados contextos, el concepto de 'Testimonio' ha servido para afianzar y consolidar relatos institucionales y para soldar con el fuego de la emocionalidad testimonial versiones de la historia o lo social ciertamente conservadoras. En los últimos años, inmersos en los que Annette Wieviorka denominó 'la era del testigo', las industrias culturales han conseguido llevar buena parte de la producción testimonial a su seno, incluyéndola en los nuevos formatos audiovisuales. Sin duda, entre esas nuevas inflexiones del testimonio hay ejemplos de posiciones antagonistas y disidentes, pero también procesos que han limado la potencialidad crítica del testimonio, reconduciéndolo a narrativas que, más que cuestionar el status quo, contribuyen a consolidarlo.

Urge, pues, releer desde una perspectiva actual los procesos sociales, culturales y políticos que han conducido al lugar difuso, y a menudo contradictorio, que los discursos testimoniales presentan en la actualidad de América Latina. Su emergencia y consolidación a lo largo de los años 50 y 60 -y su definitiva consolidación como género reconocido por el Premio Casa de las Américas en 1970- estuvo ligada a una crisis del concepto tradicional de intelectual y a la emergencia de nuevos imaginarios revolucionarios, pero también a una nueva calidad de las formas de dominación política y de los modos de la violencia social. Varias décadas después, se han instalado ideologías culturales y debates muy diferentes a aquellos en cuyo seno aparecieron esas escrituras y, desde luego, han surgido formas de dominación política y lógicas de la violencia social que eran impensables en aquella época. Urge, pues, localizar los nuevos modos del testimonio en el contexto de la globalización neoliberal y de las nuevas formas de violencia sistémica que azotan América Latina.

Así pues, esta convocatoria se plantea dos horizontes simultáneos para pensar la actualidad del testimonio. En primer lugar, historizar críticamente el recorrido de las escrituras y discursos testimoniales en América Latina, desde los años 50 hasta nuestros días, desde una perspectiva global que tenga en cuenta la variedad de prácticas y posiciones que el concepto ha recubierto y que defina el lugar que cada una de estas prácticas ha desempeñado en relación con los movimientos sociales, las políticas de Estado, los imaginarios colectivos y, si es el caso, con la esfera cultural y literaria. En segundo lugar, localizar las nuevas prácticas y lógicas del testimonio en la América Latina actual, reflexionar en torno a su lugar en las luchas sociales y culturales contemporáneas y en los debates sobre las formas de intervención política, social y cultural posibles en el mundo de la globalización desigual. 
Frente al doble reto que anunciábamos en la convocatoria, la respuesta de los colaboradores fue sin duda desigual. Por una parte, obtuvimos un altísimo número de propuestas, mucho mayor de lo esperado, que apostaban por elaborar una nueva mirada, crítica y desde metodologías de actualidad, para abordar históricamente el archivo de testimonios ya consolidado o propuestas testimoniales que habían gozado de muy poca visibilidad pero que habían desempeñado un rol importante en las luchas políticas o culturales del pasado. Por otra parte, fueron relativamente pocas las propuestas que trataban de responder al segundo de los ejes de la convocatoria: las prácticas testimoniales del presente en relación con las luchas políticas y sociales de la actualidad.

Ese desajuste nos habla de dos cuestiones simultáneas. En primer lugar, que el testimonio sigue teniendo un lugar importante en las discusiones sobre la relación entre cultura y política, y que presenta todavía una gran potencialidad para el pensamiento crítico: al repensar las políticas del testimonio consigue reconocer en ellas algunos gestos y prácticas cruciales en la cultura y la sociedad latinoamericana de las últimas décadas. En segundo lugar, que existe una dificultad para pensar la continuidad entre las formas -digamos- clásicas del testimonio y otras prácticas, discursos y acciones, propias de las luchas actuales, que podrían leerse desde el paradigma de lo testimonial. Es tarea del pensamiento crítico actual, pues, localizar y analizar esas nuevas prácticas testimoniales que, desde estilos y posiciones muy diferentes, están reorganizando en la actualidad la relación entre cultura, lucha social y práctica política y que todavía no somos capaces de reconocer con nitidez.

Las contribuciones que hemos seleccionado para este número especial creemos que suponen una aportación importante tanto para la revitalización de la historia crítica del testimonio como para sentar las bases para una reflexión crítica nueva en torno a las prácticas testimoniales del presente. Por la específica naturaleza de nuestro objeto de reflexión, hemos tratado de poner en diálogo artículos de investigación con la voz directa de algunos actores fundamentales del campo testimonial de las últimas décadas. Por ello hemos incluido en cada una de las secciones del número al menos una entrevista o documento original (un texto dramático, una serie fotográfica, una conversación cruzada, un archivo visual...) que permitieran anclar la reflexión en las circunstancias específicas de producción y circulación de las prácticas testimoniales.

El primero de los bloques del número propone una reflexión sobre las relaciones entre literatura, documentalismo, escrituras de no ficción y emergencia del testimonio desde los años cincuenta hasta los sesenta. Presenta, para ello, dos artículos de investigación en cierta medida complementarios, que 
analizan la obra seminal de Rodolfo Walsh y la de Francisco Urondo; el artículo de Victoria García pone en relación las propuestas de Walsh y Urondo con la de Julio Cortázar, poniendo el acento en el modo en que sus obras problematizaban la relación entre literatura y testimonio; el artículo de Fabiana Grasselli focaliza en los posicionamientos estético-políticos de los autores a finales de los sesenta, cruzando el análisis de su escritura con sus declaraciones programáticas en torno a lo testimonial y con el lugar que otorgaran a sus experiencias como escritores y militantes. En diálogo con estos dos artículos presentamos dos documentos valiosos e inéditos: la adaptación teatral del texto testimonial de Rodolfo Walsh Operación masacre, en versión de Jorge Curi y Mercedes Rein (1973), con una cuidada edición crítica de Victoria García; y una extensa entrevista a Hernán Valdés, escritor chileno que desde los años sesenta hasta la actualidad ha explorado la relación entre literatura, testimonio y conflicto político, especialmente desde la publicación de su testimonio, de gran impacto internacional, Tejas verdes. Diario de un campo de concentración en Chile.

El segundo bloque de colaboraciones aborda la relación de los imaginarios revolucionarios y la emergencia y consolidación de las escrituras testimoniales, centrándose en el caso de la revolución cubana. Dos artículos analizan la figura y la producción de Ernesto Che Guevara, figura central en la consolidación de las escrituras testimoniales en relación con las experiencias revolucionarias. Claudia Gilman analiza la figura del Che como icono de un tiempo y de una época que resuena en el presente, preguntándose sobre lo que nos enseña su vigencia y sobre aquello que deja a la figura del Che en estado perenne de apertura. Jaume Peris Blanes se detiene en los textos narrativos de Guevara, tratando de describirlos en su historicidad y restituirles la potencialidad revolucionaria desde la que fueron escritos. Otros dos textos abordan el complejo rol desempeñado por la Casa de las Américas en la consolidación del testimonio, a través de su premio literario, que fue el primero en incluirlo como categoría genérica. Presentamos en primer lugar una entrevista cruzada con tres intelectuales: Jorge Fornet y Luisa Campuzano, grandes conocedores del premio desde su interior, y Victoria García, investigadora especializada en el tema, en torno a las vicisitudes y efectos del premio. Incluimos en el documento una extensa serie de imágenes que forman parte del Archivo visual de Casa de las Américas y un listado de premiados y jurados desde la creación del premio hasta la actualidad. Ese documento dialoga con el artículo de Anna Forné en el que analiza los primeros años del premio y su relación con el periodo conocido con 'Quinquenio gris'. Para cerrar el bloque, el artículo de Mónica Simal plantea una contralectura de esa relación entre testimonio y políticas revolucionarias a partir de los escritos de Reinaldo Arenas, quien polemiza con los usos oficiales del testimonio dándole la vuelta al género para articular una propuesta disidente.

El tercer bloque analiza las relación, central en toda una tradición crítica, entre el testimonio y las comunidades subalternas. Se abre con un texto inédito de Margaret Randall en el que analiza su propia 
producción testimonial en relación con diversos procesos de empoderamiento y transformación social, desde los años setenta hasta la actualidad. El artículo de Nathanial Gardner apunta a una cuestión esencial: la cuestionable representatividad de los sujetos que protagonizan los testimonios ya 'clásicos' sobre las comunidades subalternas, en virtud del carácter excepcional de sus vidas. Las propuestas de Gema Palazón y Nuria Girona por una parte y de Mercè Picornell por otra abordan el caso de Rigoberta Menchú, analizando la construcción de su figura pública en continua redefinición y la polémica desatada por las acusaciones de David Stoll, que hicieron del texto testimonial de Menchú el centro de una agria pero reveladora discusión. Rocío Zavala analiza en su propuesta la subjetivación plural en el testimonio de Domitila Barrios de Chungara y las diferentes fuerzas que atraviesan su discurso. Hans FernándezBenítez, por su parte, explora un corpus poco conocido de testimonios indígenas conosureños, dando a conocer un Cono Sur polilógico con diversas formas de convivencia y representación.

El cuarto bloque retoma la relación entre los imaginarios revolucionarios y el testimonio, centrándose ahora en las guerrillas centroamericanas y en las formas variadas en que han sido representadas testimonialmente. Werner Mackenbach analiza el conjunto de la producción testimonial latinoamericana a partir de los conceptos de epopeya y parodia. Le sigue una entrevista a Margaret Randall centrada en su participación en volúmenes testimoniales relacionados con los procesos revolucionarios centroamericanos y un artículo en torno a uno de los trabajos de Randall, firmado por Leonel Delgado Aburto. En su propuesta, Verónica Rueda y Juan Carlos Vázquez se centran en la polémica incorporación de las voces de los integrantes de la Contra en la memoria de la lucha insurreccional sandinista, estableciendo un diálogo fecundo con la entrevista a Vidaluz Meneses en torno al trabajo de las Brigadas Culturales en Nicaragua. Cierran el bloque la investigación de Nathalie Narváez en torno a las figuras de la masculinidad y la feminidad en los testimonios de combatientes guatemaltecos y guatemaltecas y una entrevista a Yolanda Colom en torno a la lucha social y emancipadora en Centroamérica.

La quinta sección aborda la pluralidad de escrituras testimoniales en torno a la violencia extrema de las dictaduras militares en el Cono Sur de los setenta. Ana Forcinito analiza desde una perspectiva global los testimonios de supervivientes en relación con las políticas de memoria en Uruguay. Jaume Peris Blanes analiza los usos del testimonio en el caso chileno, desde 1973 hasta finales de la década pasada, y Paula Simón se detiene en los usos de la escritura testimonial en la postdictadura argentina. Esos trabajos dialogan con la entrevista realizada por María Teresa Johansson a Carlos Liscano, superviviente uruguayo, en torno a la escritura posible de la experiencia de la represión militar. Le siguen tres artículos más que ponen el foco en los centros clandestinos o campos de concentración: Juan Bessé y Luciana Messina analizan la emergencia de la razón militante en diversos testimonios de exdetenidos en Atila / Mansión Seré; Mariela Ávila propone un acercamiento filosófico a la relación entre 
testimonio y campo de concentración en la especificidad histórica del Cono Sur; y José Santos Herceg analiza los lugares de encuentro en el contexto concentracionario chileno. Cierra este bloque una extensa entrevista a Nora Strejilevich, sobreviviente argentina, realizada por Paula Simón.

El sexto bloque está dedicado a la relación entre fotografía, documental y testimonio, especialmente en el espacio cultural argentino. Claudia Feld aporta una reflexión en torno a las fotografías que aludieron a la práctica de la desaparición forzada en el periodo transicional. Lior Zylberman analiza el lugar del testimonio en los documentales sobre los juicios por los crímenes de la última dictadura militar. Edoardo Balleta se detiene en los usos creativos de la fotografía para aludir a los efectos de la violencia en la postdictadura y Natalia Fortuny analiza las imágenes que envuelven la 'doble desaparición’ de Julio López y desarrolla el concepto de memoria fotográfica en la Argentina reciente. El bloque se cierra con una muestra de las poderosas imágenes del fotógrafo chileno Cristian Kirby en torno a la desaparición, con ejemplos de sus tres series fotográficas en torno a los 119, colectivo de desaparecidos chilenos.

La séptima sección del número está dedicada a localizar y pensar nuevas formas y tendencias en las escrituras testimoniales, ligadas a la emergencia pública de nuevas generaciones que toman la voz con un tono y una intencionalidad diferente y al cuestionamiento de los lenguajes y lógicas de representación consolidados en las estéticas culturales de la memoria. Gabriel Gatti se pregunta sobre el lugar del testimonio en un mundo en el que la figura de la víctima posee cada vez una mayor centralidad y legitimidad cultural. Leonor Arfuch localiza algunas escrituras recientes, ligadas a la generación de los hijos de quienes vivieron la represión, que resitúan la problemática de la memoria y el testimonio a partir de un uso creativo y crítico de la autoficción. El trabajo de Rossana Nofal dialoga con el artículo de Arfuch, centrándose en las configuraciones metafóricas que cristalizan en algunas de esas ficciones, que ofrecen una nueva forma de entender la dimensión testimonial. En ese territorio entre el testimonio y la ficción, el artículo de Bernardita Llanos aborda algunas propuestas recientes en torno a las figuras de mujeres militantes que llegaron a colaborar con sus represores en un contexto de extrema violencia, y que han sido estigmatizadas culturalmente por ello. Por último, Fernando Reati nos ofrece una singular entrevista a Julián Axat sobre poesía, exclusiones contemporáneas y las múltiples dimensiones de la violencia social.

El octavo y último bloque de colaboraciones aborda la naturaleza de las nuevas violencias sociales, económicas y militares y el rol posible del testimonio en relación con ellas. Se abre con una entrevista a Pilar Calveiro sobre las nuevas violencias y las nuevas resistencias posibles en tiempos de reorganización hegemónica global. Le sigue la aportación de Elzbieta Sklodowska, que retoma alguna de sus investigaciones ya clásicas sobre el testimonio latinoamericano para revisarlas desde la distancia temporal y abrir nuevos caminos para pensarlo en la contemporaneidad. Los artículos de Martha Cecilia Herrera y 
Carol Pertuz y Elvira Sánchez-Blake y Yenifer Luna Gómez se centran en el rol del testimonio en el caso colombiano: el primero de ellos analiza el lugar del testimonio en relación con las políticas públicas de memoria y reparación; el segundo aborda los repertorios simbólicos que se apropian de los métodos y estrategias del testimonio en el contexto de los procesos de resolución del conflicto armado. El trabajo de Mercedes Alonso se detiene en las crónicas y documentales testimoniales sobre el universo de las urbanizaciones y barrios privados y el de Laura Scarabelli en el análisis del cuerpo-testigo en una novela híbrida de Diamela Eltit. Para cerrar el número, Mariana Espeleta se interroga sobre la relación entre subalternidad y testimonio hoy desde una perspectiva gramsciana y reflexiona sobre los casos de las Patronas de Veracruz y las familiares de las víctimas de Ciudad Juárez como ejemplo de prácticas testimoniales de nuevo cuño.

Este número especial ha sido coordinado en su mayor parte por Jaume Peris Blanes, a excepción de los bloques tercero y cuarto cuya coordinación ha recaído en Gema Palazón Sáez. Pero los coordinadores deseamos hacer constar nuestro agradecimiento especial a Victoria García, Luisa Campuzano y Paula Simón que propusieron nombres, ideas, contactos de gran utilidad y trabajaron para conseguir documentos, entrevistas y materiales de archivo que no hubiéramos conseguido sin ellas. Fernando Reati, Natalie Narváez y María Teresa Johansson aceptaron realizar entrevistas cruciales que de otro modo no hubieran podido tener lugar. Gabriel Gatti, con su acostumbrada efervescencia intelectual, removió conceptos, ideas y propuso direcciones posibles para repensar la potencia del testimonio desde otro lugar. Una mención especial merecen las autoras y autores que aceptaron ser entrevistados: Hernán Valdés, Jorge Fornet, Margaret Randall, Vidaluz Meneses, Yolanda Colom, Carlos Liscano, Nora Strejilevich, Julián Axat y Pilar Calveiro; y aquellos que aportaron su material creativo, como Jorge Curi y Mercedes Rein con su adaptación teatral de la obra de Walsh y Cristian Kirby con sus poderosas fotografías en torno a la desaparición, una de las cuales, perteneciente a la serie 'Lugares de desaparición', hemos utilizado como portada de este número especial.

Pero todas estas colaboraciones no hubieran podido salir adelante sin el trabajo de las personas que forman la revista y que, de algún modo, dan sentido y continuidad a esta aventura. Karolina Zygmunt y Raúl Molina llevan adelante la secretaría de redacción y las diferentes plataformas en que se publica la revista. En el caso de Karolina, se encarga además de buena parte de la comunicación con los autores y del arduo trabajo de certificación y planificación interna del la plataforma OJS. Ángela Martínez Fernández y Antonio García del Río se han encargado, junto a Jaume Peris Blanes, de la maquetación de los artículos, de su revisión y su edición final, contando con el trabajo de corrección que han realizado nuestros colaboradores Nuria Lorente Queralt, Enrique Andrade y Cristina Fernández López. A todos 
ellos, como a los autores, revisores y evaluadores que han participado de un modo u otro en este número, nuestro agradecimiento sincero y nuestra profunda gratitud.

Nos gusta pensar que, de alguna forma, el trabajo realizado en Kamchatka es el reflejo de una comunidad emergente, de contornos todavía difusos y por ello difícil de observar, que lucha por constituir no sólo nuevos discursos y representaciones, sino también nuevas relaciones sociales, políticas y afectivas y también, por supuesto, formas nuevas de construir conocimiento y de relacionarnos con él. A pesar de la nueva calidad de sus luchas, afectos y formas de vida, esa comunidad es sin duda, y aunque de forma a veces no evidente, heredera de otras comunidades del pasado, tradiciones y proyectos, algunos de los cuales fueron arrasados por las violencias de las que se habla en no pocos artículos de esta propuesta. A esa comunidad emergente, y a la potencia de lo común que resuena en ella, va pues dedicado este número. 